\title{
Investigation of energy transfer mechanisms between two adjacent phosphorescent emission layers
}

Cite as: J. Appl. Phys. 111, 113102 (2012); https://doi.org/10.1063/1.4724346

Submitted: 08 March 2012 . Accepted: 30 April 2012 . Published Online: 04 June 2012

Carola Diez, Thilo C. G. Reusch, Stefan Seidel, and Wolfgang Brütting

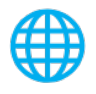

\section{ARTICLES YOU MAY BE INTERESTED IN}

Nearly 100\% internal phosphorescence efficiency in an organic light-emitting device

Journal of Applied Physics 90, 5048 (2001); https://doi.org/10.1063/1.1409582

Intrinsic luminance loss in phosphorescent small-molecule organic light emitting devices due to bimolecular annihilation reactions

Journal of Applied Physics 103, 044509 (2008); https://doi.org/10.1063/1.2884530

Operational degradation of organic light-emitting diodes: Mechanism and identification of chemical products

Journal of Applied Physics 101, 024512 (2007); https://doi.org/10.1063/1.2430922

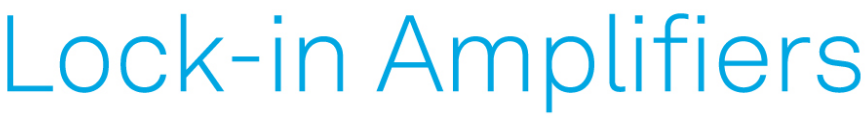

... and more, from DC to $600 \mathrm{MHz}$

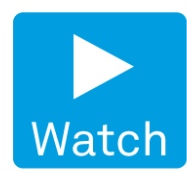




\title{
Investigation of energy transfer mechanisms between two adjacent phosphorescent emission layers
}

\author{
Carola Diez, ${ }^{1,2, a)}$ Thilo C. G. Reusch, ${ }^{1}$ Stefan Seidel, ${ }^{1}$ and Wolfgang Brütting ${ }^{2}$ \\ ${ }^{1}$ OSRAM Opto Semiconductors GmbH, Leibnizstrasse 4, 93055 Regensburg, Germany \\ ${ }^{2}$ Institute of Physics, University of Augsburg, Universitätsstrasse 1, 86159 Augsburg, Germany
}

(Received 8 March 2012; accepted 30 April 2012; published online 4 June 2012)

\begin{abstract}
The investigation of energy transfer mechanisms between two adjacent phosphorescent emission layers comprising the green emitter molecule fac-tris(2-phenly-pyridin)iridium $\left(\operatorname{Ir}(\operatorname{ppy})_{3}\right)$ and the red emitter molecule iridium(III)bis(2-methyldibenzo[f,h]quinoxaline(acetylacetonate) $\left(\operatorname{Ir}(\mathrm{MDQ})_{2}(\mathrm{acac})\right)$ is presented. We show that the performance can be enhanced by a variation of the emission layer thickness and the emitter concentration. By inserting different interlayer materials between the emission units, we demonstrate that triplet excitons are formed on the $\operatorname{Ir}(\text { ppy })_{3}$ and subsequently transferred to the $\operatorname{Ir}(\mathrm{MDQ})_{2}$ (acac) molecules via the hole transporting host material N,N'-bis(naphthalen-1-yl)-N,N'-bis(phenyl)-benzidine of the red emission layer. The variation of the interlayer thickness shows that the triplet diffusion length is several tens of nanometers. After optimization of the guest-host system an efficiency enhancement by $15 \%$ was achieved and the lifetime of the red-green emissive unit could be enhanced by $55 \%$. Additionally, it is shown that this improved red-green unit can be combined with a fluorescent blue emitter in a state-of-the-art stacked white emissive organic light emitting diode. (C) 2012 American Institute of Physics. [http://dx.doi.org/10.1063/1.4724346]
\end{abstract}

\section{INTRODUCTION}

Organic light emitting diodes (OLEDs) have attracted increasing attention, as they are promising candidates for highly efficient solid-state light sources. ${ }^{1}$ Today, their optimization is not only driven by improvement of materials but also by an optimization of layer stack concepts. ${ }^{2,3}$ In order to reach high luminous efficacies and long lifetimes, the devices need to have high quantum efficiencies. Highest efficiencies are achieved in full phosphorescent devices, since they allow, in an ideal case, full harvesting of all electrically generated singlet and triplet excitons in an OLED. ${ }^{4-6}$ However, at high current densities triplet-triplet annihilation (TTA) and triplet-polaron quenching (TPQ) may occur, which are detrimental for high efficiencies and long lifetimes. ${ }^{7}$ Therefore, it is highly desirable to improve efficiency and lifetime of phosphorescent emission units and understand the limiting factors in more detail to develop strategies for avoiding quenching effects. While the energy transfer between two fluorescent molecules ${ }^{8,9}$ or a fluorescent host and a phosphorescent dopant ${ }^{4,7}$ is well understood, detailed investigations on the fundamental transfer mechanisms across layer interfaces of two adjacent phosphorescent emission layers are rare.

In this paper, we have performed a systematic study on energy transfer and quenching mechanisms on two phosphorescent dyes in adjacent emission zones, namely, red and green emission layers comprising iridium(III)bis(2-methyldibenzo[f,h]quinoxaline(acetylacetonate) $\quad\left(\operatorname{Ir}(\mathrm{MDQ})_{2}(\mathrm{acac})\right)$ and $f a c$-tris(2-phenly-pyridin)iridium $\left(\operatorname{Ir}(\mathrm{ppy})_{3}\right)$ as emitters, respectively. The performance was investigated by a variation

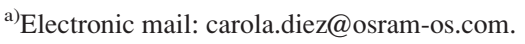

of the emitter concentration and the emission layer thickness. We found that the exciton generation zone is located at the interface between the emission layers and, therefore, high emitter concentrations lead to triplet-triplet annihilation due to a high exciton density in a narrow region of the device.

By inserting different interlayer (IL) materials between the two emission layers we demonstrate that triplet excitons are formed on the $\operatorname{Ir}(\text { ppy })_{3}$ molecules and subsequently transferred to the $\operatorname{Ir}(\mathrm{MDQ})_{2}(\mathrm{acac})$ molecules via the hole transporting host material N, $N^{\prime}$-bis(naphthalen-1-yl)-N, $\mathrm{N}^{\prime}$ bis(phenyl)-benzidine ( $\alpha$-NPD) of the red emission layer. The variation of the interlayer thickness under consideration of optical microcavity effects shows that the exciton diffusion length is several tens of nanometers.

Schwartz et al. ${ }^{10,11}$ investigated a related system comprising the emitters $\operatorname{Ir}(\mathrm{MDQ})_{2}(\mathrm{acac})$ and $\operatorname{Ir}(\mathrm{ppy})_{3}$. They showed that by inserting a fluorescent blue emitter (4P-NPD) with a small singlet-triplet splitting, blue triplets may be harvested in the adjacent emission layers (EMLs) and efficient white light emission could be observed. However, the lifetime of the devices was not discussed and we assume that the lifetime of devices comprising 4P-NPD is not comparable to other commercially available blue fluorescent emitters.

A common approach for generating white light emission is a combination of red, green, and blue phosphorescent emitters. ${ }^{12,13}$ However, available blue phosphorescent emitter systems still have limited stability thus making a combination of a highly stable blue fluorophor with red and green phosphors in so-called hybrid white devices an attractive alternative to fully phosphorescent devices. In the case of a hybrid device, energy transfer from the phosphorescent emitters to the triplet level of the fluorescent blue emitter leads to non-radiative decay and thus to a reduction in efficiency 
which should be avoided. One known approach to suppress this energy transfer is by placing phosphorescent and fluorescent emitters into single emissive units separated by a charge generation layer, thus resulting in a stacked OLED consisting of a blue (B) and a red-green (RG) unit. ${ }^{14}$ This in turn requires a profound knowledge about energy transfer mechanisms in a phosphorescent red-green emission unit.

We show that the introduction of a mixed host approach for the red and green emission layers broadens the emission zone, leading to an efficiency enhancement by $15 \%$ and an improved lifetime of the red-green unit. Furthermore, it is shown that this improved RG unit can be combined with a highly stable fluorescent blue emitter in a state-of-the-art stacked white OLED. The luminous efficacy of such a stacked white OLED was enhanced from $17 \mathrm{~lm} / \mathrm{W}$ to $23 \mathrm{~lm} / \mathrm{W}$ and the lifetime of the device was more than doubled.

The remainder of this paper is organized as follows: We start with a basic description of transfer mechanisms between two phosphorescent emission layers (Sec. II). This is followed by the experimental details of the processed redgreen emission units, the performed measurements, and optical simulations (Sec. III). In Sec. IV, the results of the discussed red and green emission layers are presented: First, for a single host approach with varying layer thickness and emitter concentrations. Second, for varying interlayer material and thickness to investigate the exciton diffusion length. After this, the mixed host approach is introduced and compared to the single host approach. Finally, the results of the improved RG unit in a stacked white OLED are shown.

\section{BASICS OF ENERGY TRANSFER MECHANISMS}

To discuss the energy transfer mechanisms occurring in a phosphorescent bichrome OLED, a simplified sketch of the energy diagram is displayed in Fig. 1(a). The shown highest occupied molecular orbital (HOMO) and lowest unoccupied molecular orbital (LUMO) energy levels are typical for organic electron transporting and hole transporting host materials. ${ }^{15}$ Holes are injected from the indium tin oxide (ITO) anode via a p-doped organic layer, the hole injection layer (HIL), into the organic stack. They accumulate at the interface between the red green emission layer and the green emission layer due to the hole blocking nature of the green
EML. Electrons are injected from the metal cathode via an n-doped electron injection layer (EIL) into the organic stack, where they accumulate at the same interface as the injected free holes. At this interface where free electrons and free holes meet, bound electron-hole states, known as excitons, can be formed. Although excitons in an amorphous organic layer are strongly localized on individual molecules (Frenkel excitons), they still can move by a series of uncorrelated hopping events by a short range Dexter transfer ${ }^{17}$ from molecule to molecule. ${ }^{18,19}$ Such movement is often referred to as random walk and can be described by Fick's 2nd law of diffusion. ${ }^{20}$ Assuming lateral homogeneity of the organic layer and isotropic material properties, this yields an exponentially decreasing steady-state exciton density with increasing distance $z$ from the exciton generation zone (assumed to be much thinner than the rest of the layer),

$$
n_{\text {exciton }}=n_{0} \cdot \mathrm{e}^{-z / L_{D}},
$$

with the exciton diffusion length

$$
L_{D}=\sqrt{D \tau},
$$

where $D$ is the diffusion coefficient, $\tau$ the exciton lifetime, and $n_{0}$ the exciton density in the exciton generation zone. In most OLED stacks, the exciton generation zone is located at the interface between a predominantly hole transporting material and a predominantly electron transporting material. ${ }^{10,11}$

As illustrated in Fig. 1, the investigated emission unit is a so-called guest-host system, where the phosphorescent emitter is doped into an organic host material. The advantage of this approach is to reduce concentration or aggregation quenching, ${ }^{21}$ which would appear for phosphorescent bulk layers or high doping concentrations. ${ }^{22}$ High quantum yields are typically achieved with a concentration of the phosphor in the guest-host system in the range of $1 \%-15 \%$. For the host material itself, certain properties are required to make it suitable for phosphorescent emitters. Most importantly, excitons created on the host site must be transferred immediately to the phosphorescent molecule for radiative recombination. Therefore, the triplet energy $\left(\mathrm{T}_{1}\right)$ of the host has to be higher compared to the guest.
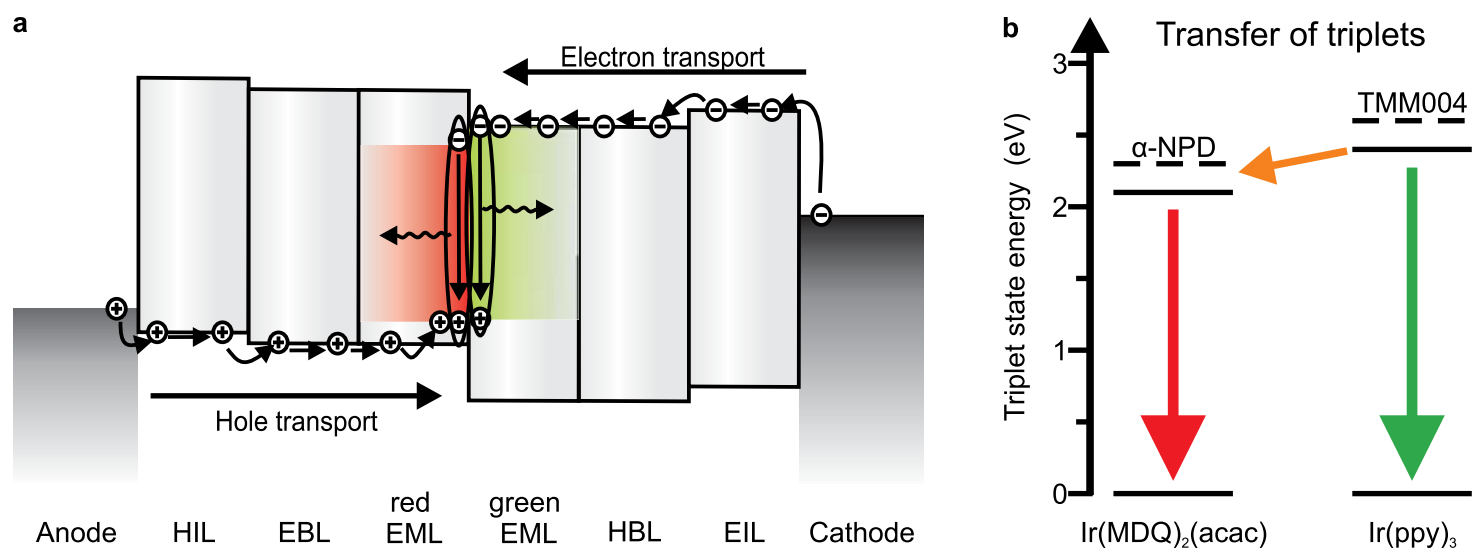

FIG. 1. (a) Simplified drawing (neglecting band bending effects) of the energy diagram of the investigated RG unit. (b) Triplet energy transfer from the phosphorescent emitter molecules $\operatorname{Ir}(\mathrm{ppy})_{3}$ to $\operatorname{Ir}(\mathrm{MDQ})_{2}(\mathrm{acac})$. The triplet state energies of the host materials $\alpha$-NPD and TMM004 (Ref. 16) are also shown. 
The triplet energies of the phosphorescent emitter molecules $\operatorname{Ir}(\mathrm{ppy})_{3}$ and $\operatorname{Ir}(\mathrm{MDQ})_{2}(\mathrm{acac})$ are displayed in Fig. 1(b). It is obvious that an energy transfer from the higher-lying triplet state of $\operatorname{Ir}(\mathrm{ppy})_{3}\left(\mathrm{~T}_{1}=2.4 \mathrm{eV}\right)^{10}$ to the triplet state of $\operatorname{Ir}(\mathrm{MDQ})_{2}(\mathrm{acac})\left(\mathrm{T}_{1}=2.1 \mathrm{eV}\right)^{10}$ may occur. At high triplet densities in the narrow exciton generation zone, triplettriplet annihilation is also likely. Additionally, if there is a nonoptimal charge balance and excess charge carriers accumulate at the interface between both layers, triplet polaron quenching may reduce the quantum efficiency at high current densities. $^{4,23}$

\section{EXPERIMENTAL DETAILS}

All devices prepared in this study exhibited an active area of $4 \mathrm{~mm}^{2}$ and were fabricated in a vacuum deposition system at an operating base pressure of $1 \times 10^{-7}$ mbar. Before evaporation, the patterned ITO glass substrates were cleaned with solvents in a multistep process and exposed to oxygen plasma. By a combinatorial evaporation process with different shadow masks, it was possible to process different devices on the same substrate successively to ensure comparability. All materials were used as received. The rate of deposition for the organic materials was $0.05 \mathrm{~nm} / \mathrm{s}$ and the substrates were not heated during evaporation. The doped layers were directly formed from the gas phase by co-evaporation of the host material(s) and the dopant. This deposition technique was also used for the green and red dye inside the host. Prior to testing, the devices were encapsulated under inert gas atmosphere with a glass lid and getter containing zeolite as dryer. Current density-voltage characteristics and electroluminescence (EL) spectra were measured using a source measurement unit (Keithley 2400-C) and a fiber spectrometer (Instrument Systems CAS 140 with TOP100). The measurement of the external quantum efficiency (EQE) was performed in an integrating sphere connected to a Keithley 2400-C and the fiber spectrometer. Prior to the measurement a calibration with a halogen lamp was performed with and without the device in order to correct for OLED self-absorption. The substrate edges were blackened to avoid influences from side emission of the OLEDs. The luminance over time was detected by a blue enhanced silicon photodiode (Photonic Detectors Inc., PDB-C613) under constant current conditions. Fig. 2 shows a simplified drawing of the device structure of the red-green emissive OLEDs. The structure of the devices was glasssubstrate $/ 110 \mathrm{~nm}$ ITO/200 $\mathrm{nm}$ doped HIL/10 nm electron and exciton blocking layer (EBL) $\alpha-\mathrm{NPD} /$ the red and green EMLs with varying thicknesses and concentrations (for details, see
Sec. IV)/10 nm hole blocking layer (HBL) and exciton blocking layer TMM004 (Ref. 16)/55 nm doped EIL/200 nm aluminum $(\mathrm{Al})$ cathode.

Optical simulations based on a dipole model were carried out. ${ }^{24,25}$ A more detailed description of the used algorithm is given by Danz et al. ${ }^{26}$ The simulations were done by assuming an exponentially decaying exciton density in the emission zone (cf. Eq. (1)) from the interface of the red-green emission unit and assuming isotropic emitter orientation. The exponential decay length (the "width" of the emission zone) is investigated in Sec. IV A and these results are included in the optical simulation.

\section{RESULTS AND DISCUSSION}

\section{A. Thickness variation}

To investigate the influence of the emission layer thickness, two different OLED series were fabricated. Using combinatorial shadow masks, it was possible to fabricate all processed OLEDs on the same ITO-substrate in the same fabrication run. The variation of the layer thicknesses could be realized by using different shadow masks for the evaporation of the EMLs. This processing technique ensures entire comparability of the devices. Fig. 3 shows the spectra measured at a constant current density of $3 \mathrm{~mA} / \mathrm{cm}^{2}$. The doping concentration for the red dye $\operatorname{Ir}(\mathrm{MDQ})_{2}(\mathrm{acac})$ in the mainly hole transporting material $\alpha$-NPD was 5\% and the doping concentration of the green dye $\operatorname{Ir}(\mathrm{ppy})_{3}$ in the mainly electron transporting material TMM004 (Ref. 16) was 11\%, respectively. With increasing red EML thickness from $7 \mathrm{~nm}$ to $11 \mathrm{~nm}$, light emission in the red spectral range $(\geq 575 \mathrm{~nm})$ is enhanced while light emission in the green spectral range $(500 \mathrm{~nm}-575 \mathrm{~nm}$ ) decreases (see Fig. 3(a)). The green EML thickness was $11 \mathrm{~nm}$ and the same for all three fabricated RG emissive OLEDs. Such an experiment can be used to probe the position and extension of the emission zone as will be explained in the following. We observe that with further increase of the red EML thickness from $11 \mathrm{~nm}$ to $15 \mathrm{~nm}$, the spectrum does not change. This indicates that the emission zone is at the interface between the predominantly hole transporting red emission layer and the predominantly electron transporting green emission layer. At $7 \mathrm{~nm}$ layer thickness, the emission zone is restricted by the layer thickness, whereas for thicknesses of $11 \mathrm{~nm}$ and higher, the emission zone is located fully within the layer. This restriction of the emission zone leads to a higher exciton density for the $7 \mathrm{~nm}$ thick EML and therefore to TTA and an EQE of 13\%,
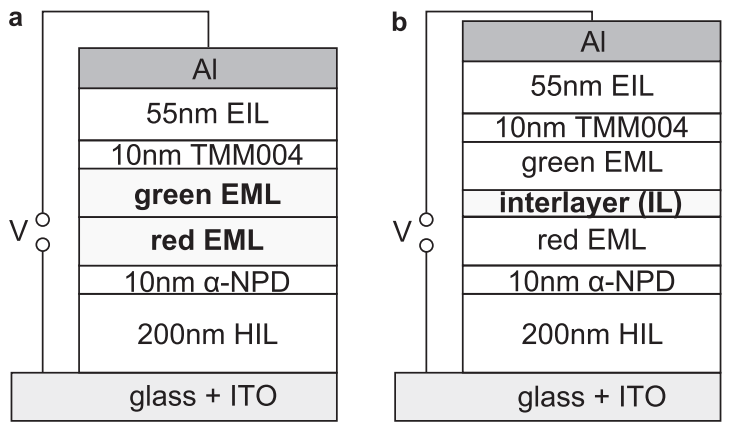

FIG. 2. Device structure of red-green emission units without (a) interlayer, with varying IL (b) and with a mixed host approach (c). 

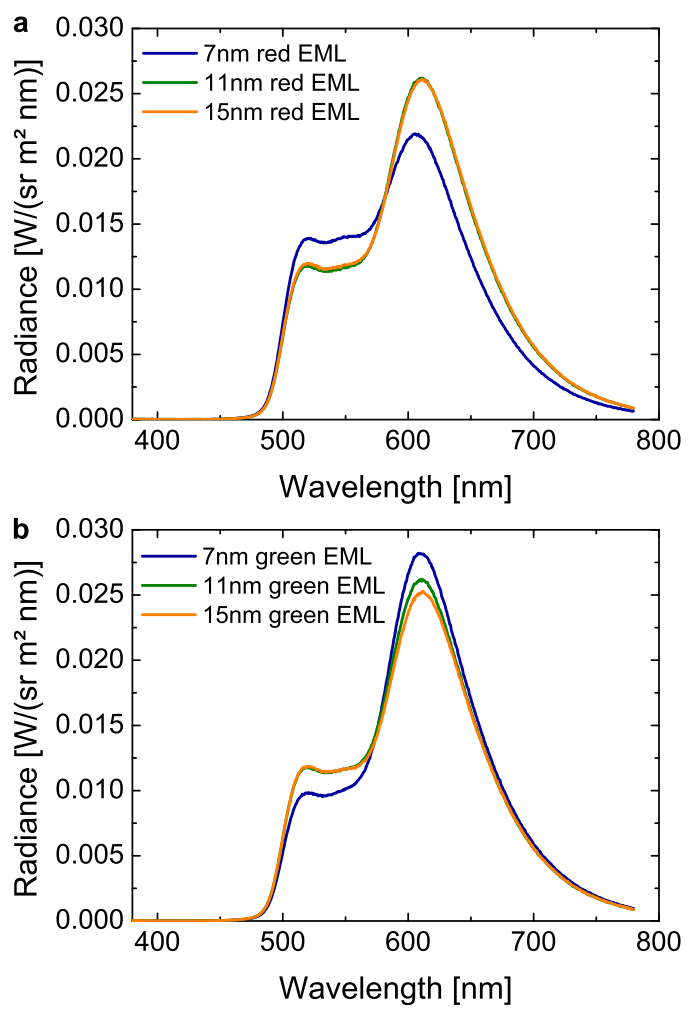

FIG. 3. Spectra measured at a constant current density of $3 \mathrm{~mA} / \mathrm{cm}^{2}$ of redgreen emission units (see Fig. 2(a)) with varying layer thickness. (a) The thickness of the red EML varied between $7 \mathrm{~nm}$ and $15 \mathrm{~nm}$, while the green EML thickness kept constant to $11 \mathrm{~nm}$. (b) The thickness of the green EML varied between $7 \mathrm{~nm}$ and $15 \mathrm{~nm}$, while the red EML thickness kept constant to $11 \mathrm{~nm}$.

whereas for the thicker layers and reduced exciton density the EQE was $14 \%$. At a distance of $11 \mathrm{~nm}$ from this interface, the steady-state exciton density (cf. Eq. (1)) has almost fully decayed to zero. Any further increase of the layer thickness would not contribute to exciton generation and light emission.

A similar experiment was performed by changing the green EML thickness while keeping the red EML thickness constant at $11 \mathrm{~nm}$. This experiment shows qualitatively the same trend as discussed before: With increasing green EML thickness, light emission in the green spectral range is enhanced while light emission in the red spectral range is decreased. Further increase in layer thickness has no impact on the emitted light. Therefore, it can be concluded that the exponentially decaying exciton generation and emission zone is located at the interface of the red and green emission layers.

\section{B. Concentration variation}

The influence of the dye molecules was investigated by a systematic variation of one phosphorescent dye concentration, keeping the other concentration unchanged. For this purpose, two sets of samples were prepared. The first had a constant $\operatorname{Ir}(\text { ppy })_{3}$ concentration of $11 \%$ and varying $\operatorname{Ir}(\mathrm{MDQ})_{2}$ (acac) concentration, while the latter had a constant $\operatorname{Ir}(\mathrm{MDQ})_{2}$ (acac) concentration of $5 \%$ and a varying $\operatorname{Ir}(\mathrm{ppy})_{3}$ concentration. The thickness of each emission layer was $10 \mathrm{~nm}$ for all six experiments. Fig. 4 shows the spectra measured at a constant current density of $3 \mathrm{~mA} / \mathrm{cm}^{2}$ and the external quantum efficiencies as a function of the current density for the two sets of fabricated RG emission units. Obviously, with increasing $\operatorname{Ir}(\mathrm{MDQ})_{2}$ (acac) concentration the green light emission is reduced. This observation can be explained as follows. By increasing the emitter concentration at the exciton generation zone, the probability of energy transfer from the higher $\mathrm{T}_{1}$ of $\operatorname{Ir}(\text { ppy })_{3}$ to the lower $T_{1}$ of $\operatorname{Ir}(M D Q)_{2}$ (acac) is enhanced (see Fig. 1(b)). However, light emission in the red spectral range was not enhanced. One possible explanation is that there is increased triple-triplet annihilation due to high triplet densities at high emitter concentrations, ${ }^{4,23}$ thus, compensating the increased transfer from green to red. To support this assumption, the EQE as a function of the current density was measured (cf. Fig. 4(b)). At a given current density, the EQE decreases with increasing $\operatorname{Ir}(\mathrm{MDQ})_{2}$ (acac) concentration showing that the total number of radiatively decaying excitons decreases. This is an indication that triplet-triplet annihilation occurs in the exciton generation zone.

Moreover, Fig. 4(b) shows that the EQE rolls off with increasing current density. This observation can be explained by increasing excess charge carrier densities in the emissive layers resulting in a higher probability of triplet-polaron quenching. ${ }^{4,23}$

We now turn to the series of constant $\operatorname{Ir}(\mathrm{MDQ})_{2}(\mathrm{acac})$ concentration and varying $\operatorname{Ir}(\mathrm{ppy})_{3}$ concentration. Here we observe that an increase in $\operatorname{Ir}(\mathrm{ppy})_{3}$ concentration leads to an enhancement of light emission in the green spectral range and a reduction of light emission in the red spectral range (cf. Fig. 4(c)). This finding can be explained by the fact that the exciton generation zone is shifting away from the interface with increasing doping concentration due to the $\operatorname{Ir}(\mathrm{ppy})_{3}$ molecules contributing to the hole conduction. ${ }^{27}$ This results in enhanced green emission and reduced red emission due to a lack of electrons in the red EML.

In Fig. 4(d), the EQE as a function of current density is shown. With increasing current density, the EQE is reduced due to triplet-polaron quenching at high current densities., ${ }^{4,23}$ Contrary to the results obtained for the $\operatorname{Ir}(\mathrm{MDQ})_{2}$ (acac) concentration variation no changes for emitter concentrations higher than $11 \%$ are observed. On the other hand, in the previous case of varying $\operatorname{Ir}(\mathrm{MDQ})_{2}$ (acac) concentration, the emission was decreased probably due to TTA (as discussed before), we do not observe this here. This indicates that TTA is not dominant here, which is again an indication that the emission zone is broadened and shifted into the green emission layer resulting in a reduced exciton density and, hence, a lower probability for TTA.

\section{Inserting interlayers and investigation of the exciton diffusion length}

In order to investigate the energy transfer mechanisms between the two adjacent phosphorescent emission units comprising $\operatorname{Ir}(\text { ppy })_{3}$ and $\operatorname{Ir}(\mathrm{MDQ})_{2}(\mathrm{acac})$, an experiment with three different interlayers between the emission units was performed. Again, all samples were prepared in the same fabrication run. For all experiments discussed in this 

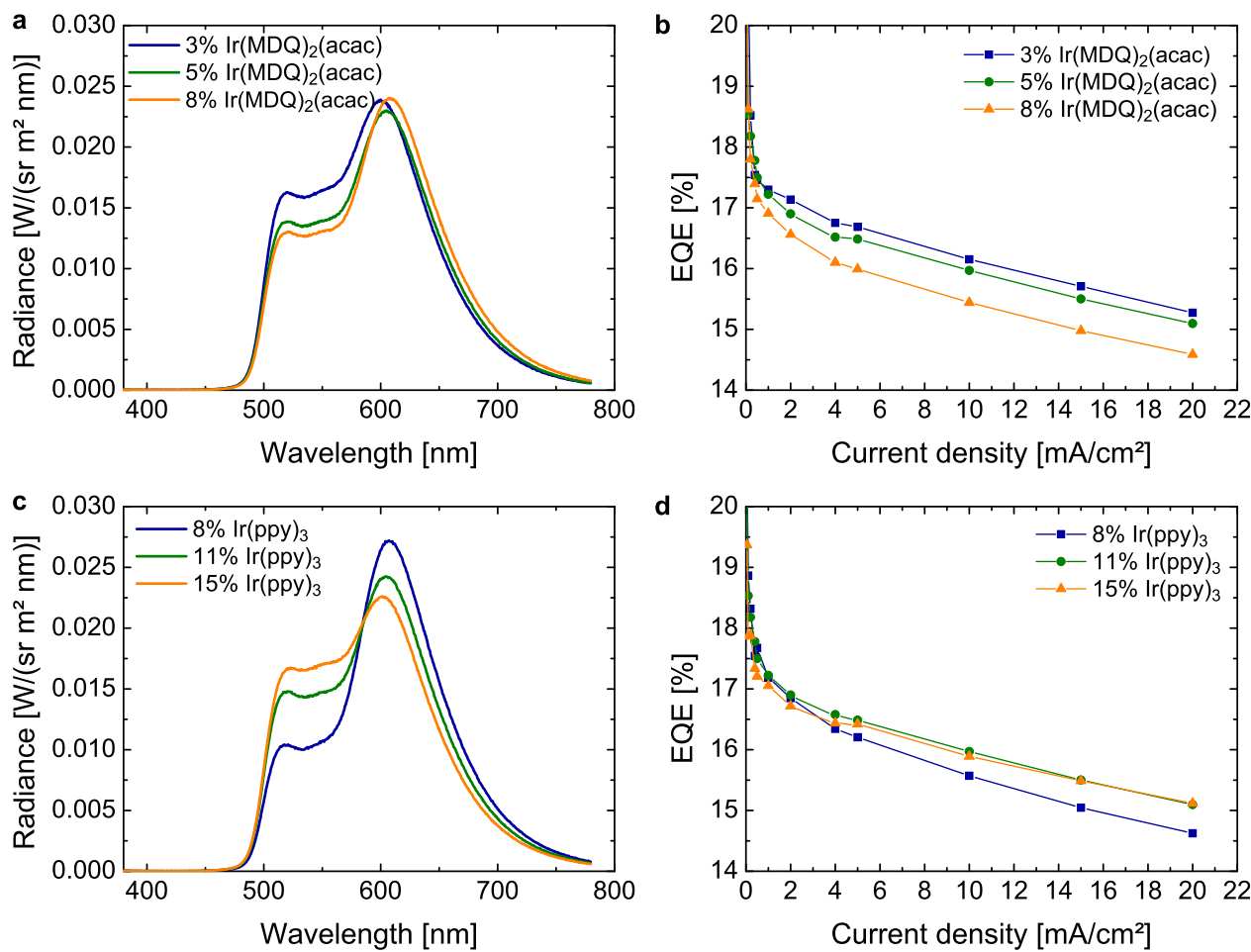

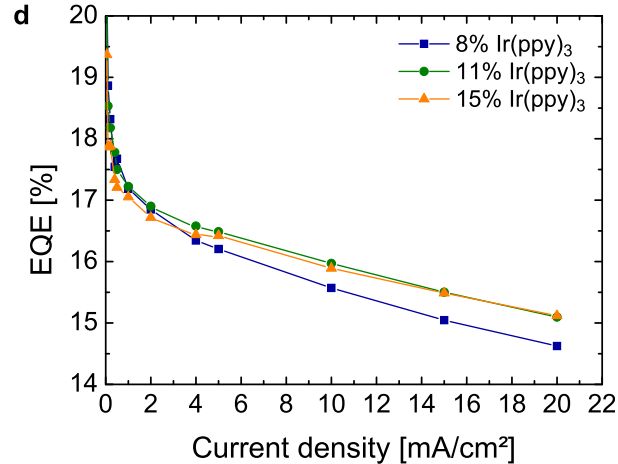

FIG. 4. Spectra measured at a constant current density of $3 \mathrm{~mA} / \mathrm{cm}^{2}$ ((a) and (c)) and external quantum efficiencies ((b) and (d)) of red-green emission units (see Fig. 2(a)) with varying emitter concentration. (a) and (b) Concentration variation of the red dye $\operatorname{Ir}(\mathrm{MDQ})_{2}(\mathrm{acac})$, while the concentration of the green dye $\operatorname{Ir}(\mathrm{ppy})_{3}$ was $11 \%$. (c) and (d) Concentration variation of the green dye $\operatorname{Ir}(\mathrm{ppy})_{3}$, while the concentration of the red dye $\operatorname{Ir}(\mathrm{MDQ})_{2}(\mathrm{acac})$ was $5 \%$. subsection, the thickness of both EMLs was $10 \mathrm{~nm}$ and the doping concentration of $\operatorname{Ir}(\mathrm{MDQ})_{2}$ (acac) in $\alpha$-NPD was $5 \%$ and the doping concentration of $\operatorname{Ir}(\mathrm{ppy})_{3}$ in TMM004 was $11 \%$, respectively. The first one was the reference experiment with an RG emission unit without interlayer as displayed in Fig. 2(a). In the second experiment, a $3 \mathrm{~nm}$ thick $\alpha$-NPD IL was inserted between the emission units (see Fig. 2(b)). $\alpha$-NPD is a hole transporting, but electron blocking material with a triplet energy $\left(\mathrm{T}_{1}=2.3 \mathrm{eV}\right)^{10,28}$ slightly lower than $\operatorname{Ir}(\mathrm{ppy})_{3}\left(\mathrm{~T}_{1}=2.4 \mathrm{eV}\right)$ but higher than $\operatorname{Ir}(\mathrm{MD}-$ Q) 2 (acac) $\left(\mathrm{T}_{1}=2.1 \mathrm{eV}\right)$ (see Fig. 1(b)). In contrast, the $3 \mathrm{~nm}$ thick interlayer inserted in the third experiment is a one-toone mixture of an electron transporting material (TMM004) and the well-known hole transporting material $4,4^{\prime}, 4^{\prime \prime}$-Tris (carbazol-9-yl)triphenylamine (TCTA). Therefore, this interlayer can be seen as ambipolar. This particular material combination was chosen because of its high triplet energy ${ }^{11}$ to block triplet diffusion from $\operatorname{Ir}(\mathrm{ppy})_{3}$ through the TMM004:TCTA IL to $\operatorname{Ir}(\mathrm{MDQ})_{2}$ (acac). Fig. 5 shows the spectra measured at a constant current density of $3 \mathrm{~mA} / \mathrm{cm}^{2}$ as well as the EQE with respect to the current density of the $\mathrm{RG}$ emission units with varying IL materials and a reference device without IL. It is a reasonable assumption that the exciton generation zone is located at the interface between the hole transporting $\alpha$-NPD IL and the green emission layer, where the majority of free holes and electrons meet. If the dominant transfer mechanism would be direct energy transfer from the green dye to the red dye, increasing the spacing between the two emitters should correspondingly decrease red emission, because the Dexter transfer length is of the order of $1 \mathrm{~nm} .{ }^{17,29}$ By contrast, the spectrum of the device with the $\alpha$-NPD IL shows the same characteristics as the reference device in the red spectral range but a slightly increased light emission in the green spectral range (cf.
Fig. 5(a)). This observation can be explained as follows. Due to the fact that the triplet energy of $\alpha$-NPD lies between the triplet energy of $\operatorname{Ir}(\mathrm{ppy})_{3}$ and $\operatorname{Ir}(\mathrm{MDQ})_{2}$ (acac), this observation indicates that the energy transfer from the green phosphor is via triplet exciton diffusion in the $\alpha$-NPD IL and not directly to the red phosphor. The slight increase in green
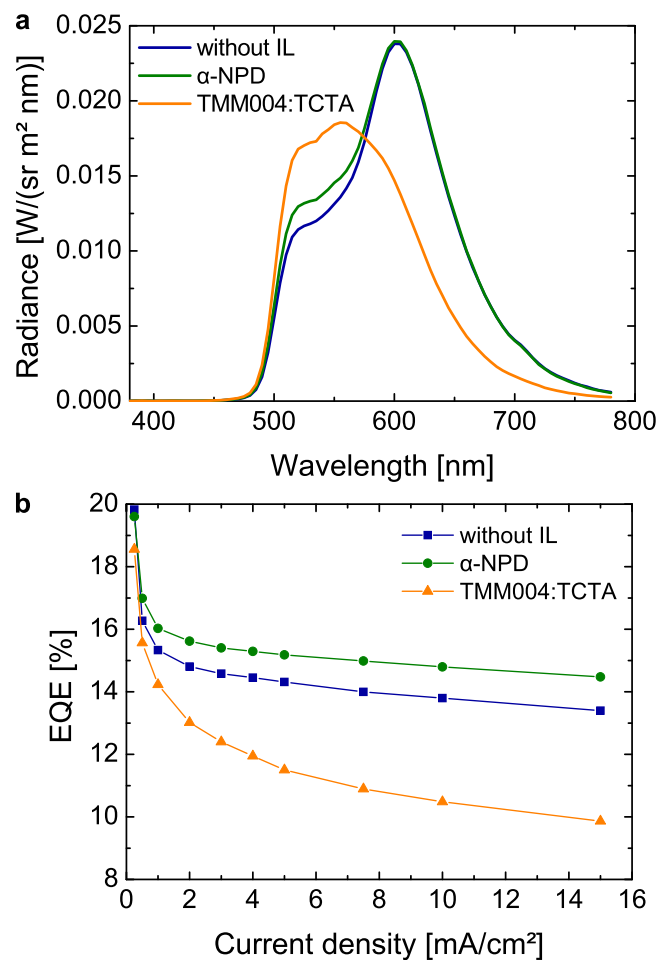

FIG. 5. Spectra measured at a constant current density of $3 \mathrm{~mA} / \mathrm{cm}^{2}$ (a) and external quantum efficiencies (b) of red-green emission units with varying interlayer material inserted between the red and green EML (see Fig. 2(b)). 
emission can be explained by a reduced triplet accumulation at the interface due to energy transfer to the $\alpha$-NPD IL and therefore reduced TTA. This efficiency enhancement can also be found in the EQE measurement displayed in Fig. 5 (b). This clearly shows that a broadening of the emission zone by the $\alpha$-NPD IL yields an efficiency enhancement due to reduced annihilation processes.

It is remarkable that the spectrum with the TMM004: TCTA IL strongly differs from the spectrum without IL and the spectrum of the device with the $\alpha$-NPD IL (cf. Fig. 5(a)). Even though electrons can enter the red emission layer, there is nearly no light emission in the red spectral range. Therefore, we can assume that the exciton generation zone is located at the interface between the TMM004:TCTA IL and the green emission layer or even shifted into the latter one. In the green EML, all created excitons are transferred to triplets of the green phosphor, which may decay radiatively. However, triplet diffusion to $\operatorname{Ir}(\mathrm{MDQ})_{2}$ (acac) is not possible through the TMM004:TCTA IL. The EQE data (see Fig. 5(b)) reveal a reduction in efficiency for the device with the TMM004:TCTA IL compared to the device without IL. One hypothesis is that by hindering triplet diffusion from $\operatorname{Ir}(\mathrm{ppy})_{3}$ molecules to $\operatorname{Ir}(\mathrm{MDQ})_{2}$ (acac) molecules, high triplet densities at the interface occur resulting in enhanced triplet-triplet annihilation.

A consistent model explaining the above observation is that the excitons are generated on the $\operatorname{Ir}(\mathrm{ppy})_{3}$ molecules and transferred via the triplet level of $\alpha-N P D$ to the $\operatorname{Ir}(\mathrm{MDQ})_{2}$ (acac) molecules. We now turn to the investigation of the triplet exciton diffusion length in $\alpha$-NPD. For optimized OLED architectures, it is essential to know the exact location and extent of the exciton generation and emission zone. Therefore, the thickness of the IL was varied between $0 \mathrm{~nm}$ and $40 \mathrm{~nm}$ in $5 \mathrm{~nm}$ steps. With rising layer thickness, the distance from $\operatorname{Ir}(\mathrm{ppy})_{3}$ molecules to $\operatorname{Ir}(\mathrm{MDQ})_{2}$ (acac) molecules is enlarged, which should result in a reduction in light emission in the red spectral range. All devices were fabricated in the same run on a single ITO-substrate using combinatorial shadow masks and with the same organic layer thicknesses, except for the $\alpha$-NPD IL, to ensure comparability. Exemplarily, the spectra for $0 \mathrm{~nm}, 20 \mathrm{~nm}$, and $40 \mathrm{~nm}$ IL thickness measured at a constant current density of $3 \mathrm{~mA} / \mathrm{cm}^{2}$ are displayed in Fig. 6(a). In this case, the red emission layer can be seen as a sensing layer for the exciton density at a specific distance $z$ from the exciton generation zone at the interface of the green EML and the IL (cf. Eq. (1)). ${ }^{30,31}$ Obviously, the probability for triplet exciton diffusion through the IL without quenching or non-radiative decay is reduced with increasing layer thickness. Hence, the emission in the red spectral range is decreasing as observed in the measurement. To exclude that this decrease is only due to an optical effect, simulations based on a dipole model were performed. In these simulations, we assumed isotropic dipoles with the same emitter strength and an exponential decay of the triplet exciton density in the exciton generation zone within $10 \mathrm{~nm}$ from the interface, as we found in Sec. IV A. These emitter distributions for both the green and the red emitter were not changed during the simulations. By inserting the IL and increasing the IL thickness, the position of the red emission
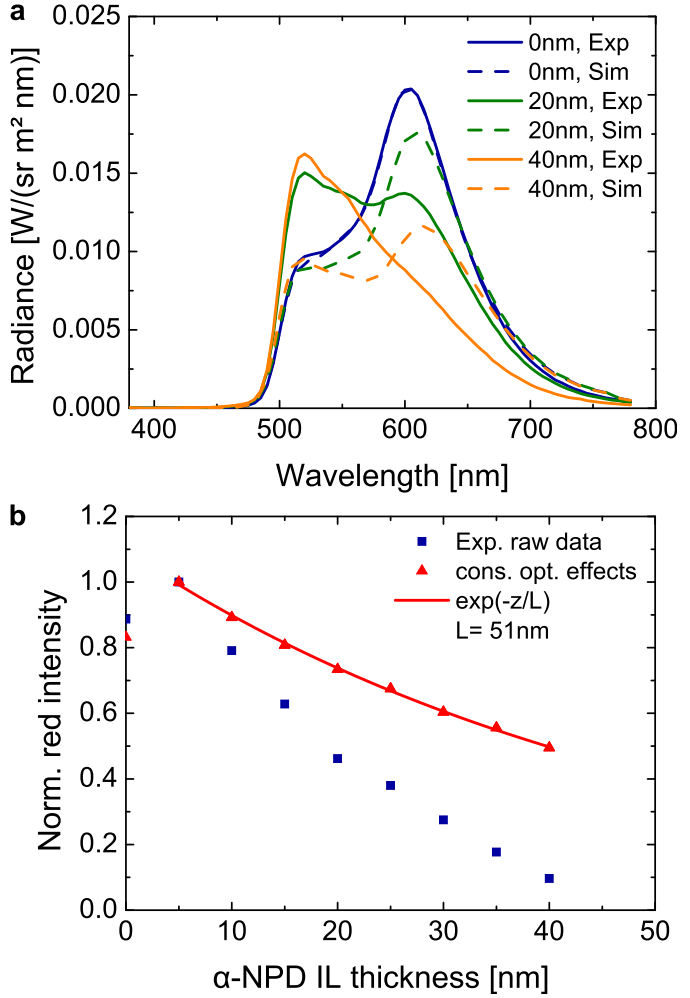

FIG. 6. (a) Experimental (solid lines) and optically simulated (dashed lines) spectra of red-green emission units with varying $\alpha$-NPD interlayer thickness. (b) Normalized red intensity vs. $\alpha$-NPD IL thickness. Comparison of experimental raw data without correcting for optical effects (squares) and with considering optical effects (triangles). A triplet exciton diffusion length of $51 \mathrm{~nm}$ can be estimated assuming delta-like exciton generation.

unit is shifted away from its optical intensity maximum resulting in a decrease in red emission but unchanged green emission (cf. Fig. 6(a)). By contrast, in the experiment we found a stronger reduction in the red spectral range but an increased light emission in the green spectral range. This finding cannot be explained purely by an optical effect but is attributed to a reduced triplet energy transfer with increasing IL thickness.

The deconvolution of the experimentally measured spectra into the contribution of red emission with rising IL thickness (squares) is displayed in Fig. 6(b). All data shown are normalized to the value at $5 \mathrm{~nm}$ IL thickness. The data for the IL thickness of $0 \mathrm{~nm}$ are not considered for the following analysis, because direct Dexter transfer from the green dye to the red dye can occur and superimpose the diffusion process via $\alpha$-NPD. As discussed before (cf. Fig. 6(a)) in addition to the exciton diffusion the red emission is affected by microcavity effects. Based on simulations, we have compensated the deconvoluted data for the microcavity effects. Hence, corrected data considering these optical effects are also shown in Fig. 6(b). The red emission is decreasing exponentially (triangles) and by fitting Eq. (1) to the data and assuming delta-like exciton generation at the interface between the green EML and the IL, we can extract an exciton diffusion length of about $51 \mathrm{~nm}$. We point out that without correcting the optical microcavity effects a much shorter triplet exciton diffusion length of $19 \mathrm{~nm}$ would be inferred. A similar experiment and analysis was applied by 
Baldo et al. ${ }^{30}$ Beierlein et al., ${ }^{31}$ and Schwartz et al. ${ }^{10}$ The latter performed an experiment with a related system, where they investigated the triplet exciton diffusion length in the fluorescent blue emitter material 4P-NPD, and extracted a comparable value of $54 \mathrm{~nm} .{ }^{10}$ Our value of $51 \mathrm{~nm}$ is in good agreement with their findings.

\section{Mixed host approach}

In this subsection, we discuss the impact of a mixed host approach on the efficiency and lifetime of phosphorescent emission units. In Sec. IV A, we found for the single host system that the exciton generation zone is located at the interface between the red and the green emission layers. Therefore, only a limited number of emitter molecules may contribute to photon generation. The idea behind the mixed host approach is to broaden the exciton generation zone by using ambipolar host materials in both emission layers to reduce the charge carrier confinement. For this purpose, two bichrome RG emitting OLEDs were fabricated. The first one is based on a single host approach meaning that the red and green dyes are doped in a predominantly hole transporting host $(\alpha-\mathrm{NPD})$ and a predominantly electron transporting host (TMM004), respectively. In the second one, an electron transporting material (TMM004) is added to the red emission layer. Therefore, co-evaporation of three different organic materials was necessary making the fabrication process more sophisticated. However, one can employ materials which are part of the OLED layer architecture anyway, as demonstrated here with the host material of the green emission layer (TMM004). With this approach, it is possible that electrons can enter the red emission layer and excitons may be generated in a broader zone.

Due to the fact that there is no stable hole transporting material with a larger triplet energy than $\operatorname{Ir}(\mathrm{ppy})_{3}$, the approach for the green EML had to be adapted. It is well known that $\operatorname{Ir}(\mathrm{ppy})_{3}$ has a high hole mobility ${ }^{27}$ and hence holes can enter the green emission layer via $\operatorname{Ir}(\mathrm{ppy})_{3}$ molecules. By adding an inert filler material (TMM060) ${ }^{16}$ to the green EML, the charge carrier balance can be improved by reducing the fraction of the electron conductive material (TMM004). Varying the composition of the mixed host for both emission layers is a possibility to tune the location and width of the exciton generation zone and, therefore, the emitted color of the OLED. Instead of co-evaporating three different materials in a mixed host approach, another possibility to broaden the exciton generation zone could be the use of a suitable ambipolar host material. This would simplify the fabrication process. However, such a material with the desired properties was not available and it seems difficult to tailor such a host molecule fulfilling the electrical and optical requirements.

Fig. 7(a) shows the comparison of the spectra of the redgreen emission units based on the single host system and the mixed host system, respectively. Both spectra were measured at a constant current density of $3 \mathrm{~mA} / \mathrm{cm}^{2}$ resulting in comparable color coordinates of CIE (0.50/0.48). This shows that the fraction of the different material components in the mixed host system was chosen well so that the emission
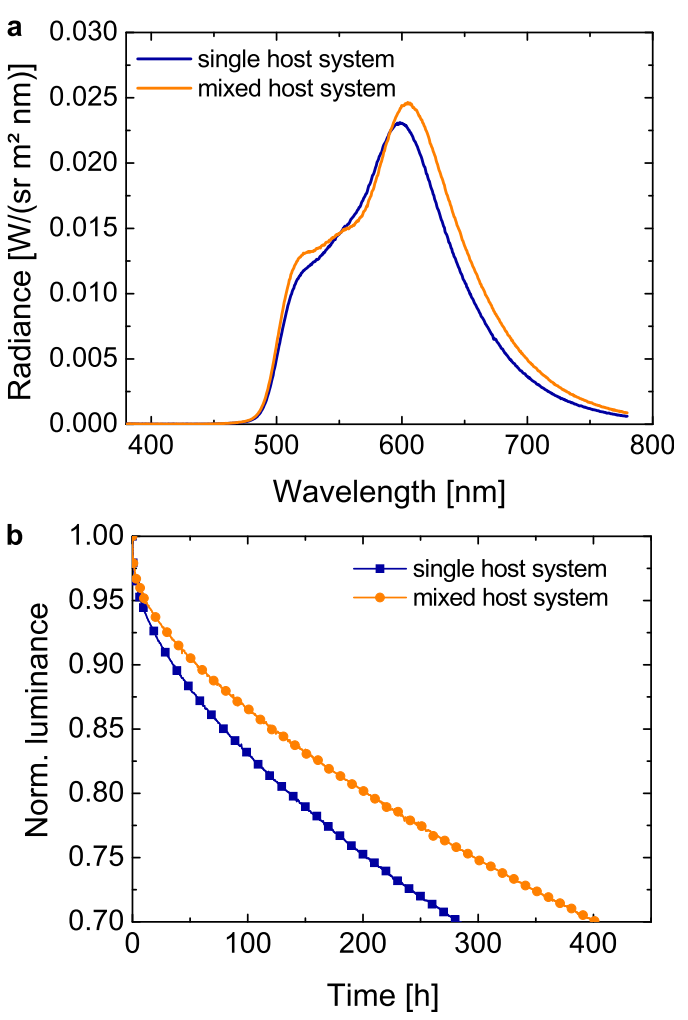

FIG. 7. Spectra measured at a constant current density of $3 \mathrm{~mA} / \mathrm{cm}^{2}$ (a) and normalized luminance versus time (b) for a single host and mixed host system (see Fig. 2(b)), respectively. The lifetime measurements were done at an initial luminance of $4000 \mathrm{~cd} / \mathrm{m}^{2}$.

zone broadened equally and the shift in its center position was negligible. It is striking that the radiance of the mixed host system is higher compared to the single host system. This means that the mixed host system is more efficient compared to the single host system. The external quantum efficiency at $3 \mathrm{~mA} / \mathrm{cm}^{2}$ for the single host system was $14 \%$, whereas the EQE for the mixed host system was improved to $16 \%$. This efficiency enhancement of $15 \%$ (rel.) can be explained by a reduction in TTA due to a broader exciton generation zone and hence reduced triplet density at the interface. The measured luminance with increasing current density shows a pronounced bending for the single host approach at high current densities whereas this bending is reduces for the mixed host approach (not shown here) which is an indication for reduced quenching.

Another major advantage of the mixed host system is shown in Fig. 7(b) where the lifetime measurement is presented. An accelerated measurement at an initial luminance of $4000 \mathrm{~cd} / \mathrm{m}^{2}$ under constant current conditions for both devices was performed and the data normalized to this initial value are displayed. The time to $70 \%$ of the initial value $\left(\mathrm{LT}_{70}\right)$ for the single host system is $280 \mathrm{~h}$, whereas for the mixed host system it is over $400 \mathrm{~h}$. The lifetime at a common initial luminance of $1000 \mathrm{~cd} / \mathrm{m}^{2}$ can be easily calculated from the measured data by using the well-known relationship $L_{0}^{n} \times \tau=$ const. $^{32}$ with the initial luminance $L_{0}$, the elapsed time $\tau$ and assuming an acceleration factor $n=1.5$. This results in an extrapolated lifetime for the single host device of $2200 \mathrm{~h}$ and an enhanced lifetime of the mixed host devices 
of approximately $3400 \mathrm{~h}$. We have to point out that by applying the mixed host approach the lifetime of the RG emission unit could be enhanced by 55\%. One possible explanation is that due to the broadening of the exciton generation zone, more molecules may contribute to light generation. The stress for each molecule is reduced resulting in an enhanced lifetime for the device. This clearly demonstrates the superior performance of the investigated mixed host system compared to the single host system in phosphorescent OLEDs.

\section{E. Stacked white emissive OLED}

For solid-state lighting applications white light emission is required. Therefore, light emission in the blue spectral range $(440 \mathrm{~nm}-500 \mathrm{~nm})$ has to be added to the light emission of the red-green emission unit. Difficulties in finding a stable blue phosphorescent emitter system makes the combination of a stable blue fluorophor with red and green phosphors in so-called hybrid white devices an attractive alternative to fully phosphorescent devices. For avoiding unwanted energy transfer from the phosphorescent emitters to the triplet energy of the fluorescent blue emitter, separation of the emission units by vertical stacking of the blue emission unit on top of the RG emission unit is an attractive option. Fig. 8(a) shows the luminous efficacy of two stacked RG + B white emitting OLEDs. The blue curves represent the experimental results before the optimization of the RG emission unit with the single host approach and the orange curves represent the results after the optimization of the RG emission unit with the mixed host approach as discussed in Sec. IV D.
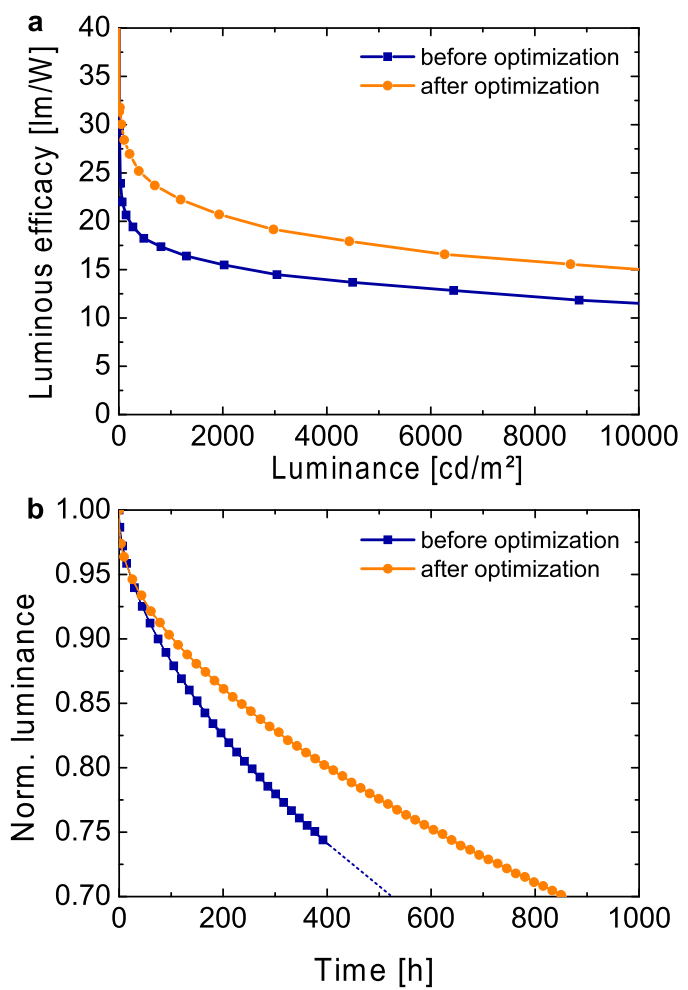

FIG. 8. Luminous efficacy (a) and normalized luminance versus time (b) of two stacked RG $+\mathrm{B}$ white emitting OLEDs before and after optimization of the red-green emission unit, respectively. The lifetime measurements were done at an initial luminance of $4000 \mathrm{~cd} / \mathrm{m}^{2}$.
However, as discussed in the last section, the fabrication process is more complicated due to the co-evaporation of three different organic materials. A good deposition rate control is required to cope with this challenge.

The luminous efficacy at a common luminance of $1000 \mathrm{~cd} / \mathrm{m}^{2}$ for the device before optimization is $17 \mathrm{~lm} / \mathrm{W}$, whereas for the device after optimization of the red-green emission unit it is improved to $23 \mathrm{~lm} / \mathrm{W}$. This increase can be attributed to the improved red-green emission unit and to a slight color shift towards the green spectral range.

One of the most important parameters in real OLED applications is the lifetime of the devices. Therefore, an accelerated lifetime measurement at an initial luminance of $4000 \mathrm{~cd} / \mathrm{m}^{2}$ was performed. The luminance decay over the operating time is presented in Fig. 8(b). From this data, the extrapolated lifetime for the common luminance of $1000 \mathrm{~cd} / \mathrm{m}^{2}$ of the device before optimization is $3350 \mathrm{~h}$, whereas for the device after optimization of the red-green emission unit it is $7000 \mathrm{~h}$. These results demonstrate that a profound knowledge about transfer mechanisms between adjacent phosphorescent emitters and exciton management are essential for optimizing state-of-the-art stacked white OLEDs.

\section{CONCLUSION}

We have investigated the transfer mechanisms between two adjacent phosphorescent emission layers by a systematic study of the impact of emission layer thickness and emitter concentration on the performance of the emission units. By inserting different interlayer materials between the emission layers we demonstrated that triplet excitons are formed on the green dye $\operatorname{Ir}(\mathrm{ppy})_{3}$ and subsequently transferred to the red dye $\operatorname{Ir}(\mathrm{MDQ})_{2}$ (acac) via the host material $\alpha$-NPD of the red emission layer. The thickness variation of an $\alpha$-NPD IL shows that the triplet exciton diffusion length is $51 \mathrm{~nm}$, which is in good agreement with literature values of comparable systems. Furthermore, we showed that the introduction of a mixed host approach broadens the exciton generation zone resulting in an enhanced efficiency and long-term stability of the red-green emission unit. Finally, the improved red-green emission unit was combined with a blue fluorescent emission unit in a state-of-the-art stacked white OLED. The luminous efficacy was enhanced from $17 \mathrm{~lm} / \mathrm{W}$ to $23 \mathrm{~lm} / \mathrm{W}$, while the lifetime of the device was more than doubled.

\section{ACKNOWLEDGMENTS}

The authors would like to thank the German Federal Ministry of Education and Research (BMBF) for funding part of this work under Contract No. FKZ 13N10474 (TOPAS 2012).

\footnotetext{
${ }^{1}$ NanoMarkets, OLED Lighting Global Market Forecasts May 2011, www.nanomarkets.net.

${ }^{2}$ Y. Sun, N. Giebink, H. Kanno, B. Ma, M. Thompson, and S. Forrest, Nature 440, 908 (2006).

${ }^{3}$ S. Su, E. Gonmori, H. Sasabe, and J. Kido, Adv. Mater. 20, 4189 (2008).

${ }^{4}$ M. Baldo, D. O'Brien, Y. You, A. Shoustikov, S. Sibley, M. Thompson, and S. Forrest, Nature 395, 151 (1998).

${ }^{5}$ G. He, M. Pfeiffer, K. Leo, M. Hofmann, J. Birnstock, R. Pudzich, and J. Salbeck, Appl. Phys. Lett. 85, 3911 (2004).
} 
${ }^{6}$ B. D'Andrade, R. Holmes, and S. Forrest, Adv. Mater. 16, 624 (2004).

${ }^{7}$ M. Baldo, C. Adachi, and S. Forrest, Phys. Rev. B 62, 10967 (2000).

${ }^{8}$ T. Förster, Discuss. Faraday Soc. 27, 7 (1959).

${ }^{9}$ M. Berggren, A. Dodabalapur, R. Slusher, and Z. Bao, Nature 389, 466 (1997).

${ }^{10}$ G. Schwartz, S. Reineke, T. Rosenow, K. Walzer, and K. Leo, Adv. Funct. Mater. 19, 1319 (2009).

${ }^{11}$ G. Schwartz, S. Reineke, K. Walzer, and K. Leo, Appl. Phys. Lett. 92, 053311 (2008).

${ }^{12}$ J. Lee, H. Chu, J. Lee, K. Song, and S. Lee, J. Nanosci. Nanotechnol. 8, 5185 (2008).

${ }^{13}$ S. Reineke, F. Lindner, G. Schwartz, N. Seidler, K. Walzer, B. Lüssem, and K. Leo, Nature 459, 234 (2009).

${ }^{14}$ S. Pieh, M. Kim, C. Sung, J. Seo, H. Choi, C. Han, and Y. Tak, SID Int. Symp. Digest Tech. Papers 60, 903-906 (2009).

${ }^{15}$ Y. Tyan, Y. Rao, X. Ren, R. Kesel, T. Cushman, W. Begley, and N. Bhandari, SID Int. Symp. Digest Tech. Papers 60, 895 (2009).

${ }^{16}$ TMM004 and TMM060 purchased from Merck KGaA, Darmstadt, Germany.

${ }^{17}$ D. O’Brien, M. Baldo, M. Thompson, and S. Forrest, Appl. Phys. Lett. 74, 442 (1999).

${ }^{18}$ D. Dexter, J. Chem. Phys. 21, 836 (1953).

${ }^{19}$ W. Brütting, Physics of Organic Semiconductors (Wiley-VCH, 2005).
${ }^{20}$ D. Fick, London, Edinburgh Dublin Philos. Mag. J. Sci. 10, 30 (1855).

${ }^{21}$ Y. Kawamura, J. Brooks, J. Brown, H. Sasabe, and C. Adachi, Phys. Rev. Lett. 96, 17404 (2006).

${ }^{22}$ Y. Kawamura, K. Goushi, J. Brooks, J. Brown, H. Sasabe, and C. Adachi, Appl. Phys. Lett. 86, 071104 (2005).

${ }^{23}$ S. Reineke, K. Walzer, and K. Leo, Phys. Rev. B 75, 125328 (2007).

${ }^{24}$ R. Chance, A. Prock, and R. Silbey, Adv. Chem. Phys. 37, 1 (1978).

${ }^{25}$ B. Krummacher, S. Nowy, J. Frischeisen, M. Klein, and W. Brütting, Org. Electron. 10, 478 (2009).

${ }^{26}$ N. Danz, R. Waldhäusl, A. Bräuer, and R. Kowarschik, J. Opt. Soc. Am. B 19, 412 (2002).

${ }^{27}$ C. Adachi, Y. Kawamura, K. Goushi, and A. Endo, Oyo Butsuri 75, 1465 (2006).

${ }^{28}$ J. Staudigel, M. Stößel, F. Steuber, and J. Simmerer, J. Appl. Phys. 86, 3895 (1999).

${ }^{29}$ M. Baldo, M. Thompson, and S. Forrest, Pure Appl. Chem. 71, 2095 (1999).

${ }^{30}$ M. Baldo, D. O'Brien, M. Thompson, and S. Forrest, Phys. Rev. B 60, 14422 (1999).

${ }^{31}$ T. Beierlein, B. Ruhstaller, D. Gundlach, H. Riel, S. Karg, C. Rost, and W. Riefl, Synth. Met. 138, 213 (2003).

${ }^{32}$ H. Aziz, Z. D. Popovic, and N.-X. Hu, Appl. Phys. Lett. 81, 370 (2002). 